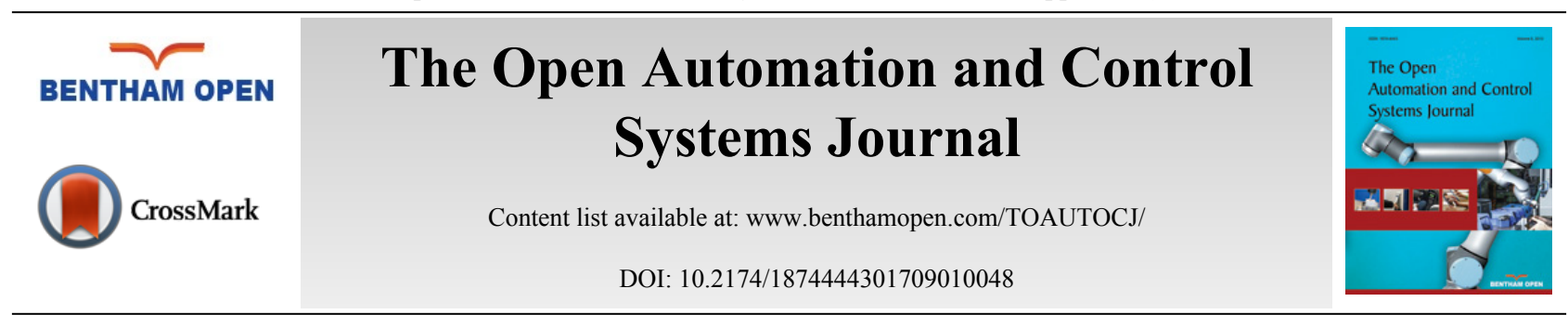

RESEARCH ARTICLE

\title{
Maintenance Optimizing of Production Systems by Reliability: Different Methods Applied
}

\author{
Kerboua Bachir ${ }^{*}$, Belabed Youcef and Bensaid Ismail \\ Mechanical engineering department, Faculty of Technology, University of Tlemcen, Algeria
}

Received: October 30, 2016

Revised: February 15, 2017

Accepted: March 30, 2017

\section{Abstract:}

Objective:

The work presented in this paper is to analyze the maintenance process that severely affects the performance of workshops and affects their operating cost and life span of equipment.

\section{Introduction:}

Any equipment or installation is subject during his lifetime, for two processes, the operating and the maintenance process.The operating process is to produce goods or services according to requirements, while the maintenance process is to maintain good working equipment or systems and improve their performance.

\section{Materials and Methods:}

Several techniques and methods have been developed to improve the maintenance managers and to choose the type of service based on financial and material resources available the company.

\section{Results:}

Our rehears is to optimize the maintenance of the boiler shop that distributes steam for air conditioning and humidity levels of the four workshops of the Denitex-Sebdou company. The facilities of this workshop require a lot of action during the year.

\section{Conclusion:}

The reliability tool used is based on the model of Pareto and AMDEC method to optimize equipment maintenance of the boiler which is considered the heart of the production at the complex.

Keywords: Strategy, Maintenance, Optimization, Modeling, Reliability, AMDEC, Preventive system.

\section{INTRODUCTION}

In the development cycle of a manufactured product, the validation phase solution is a fundamental step. It is essential to verify that the performance specifications conform to specifications, using tests during the design phase. The designer is primarily interested in the product behavior and in manufacturing environment (manufacturing conditions trade, etc.) constraints, as a direct impact on its characteristics or final performance. For the user, the concern is whether the product is able to fulfill its mission in the operating environment (scenarios use, climatic conditions, etc.) [1 - 5].

The maintenance optimization in the context of sustainable development is to find a balance between preventive and corrective maintenance while meeting the goals and standards of production and operation. We must then determine the

\footnotetext{
* Address correspondence to this author at the Mechanical engineering department, Faculty of Technology, University of Tlemcen, Algeria; Tel: (+213)552276261; E-mail: kerbouac@yahoo.fr
} 
moments of optimal maintenance and actions to maximize the decision criterion for monitoring equipment and degradation. This decision criterion is based on both the maintenance cost and the availability or safety [1 - 5]. Fig. (1) is an illustration of the effects of maintenance frequency on the costs or corrective maintenance or preventive maintenance following a meeting of the heads of production units or operations at "Denitex Sebdou Manufacturing". The Maintenance department has committed a responsibility of equipment degradation, the need for high availability and facilities for better optimization of equipment reliability.

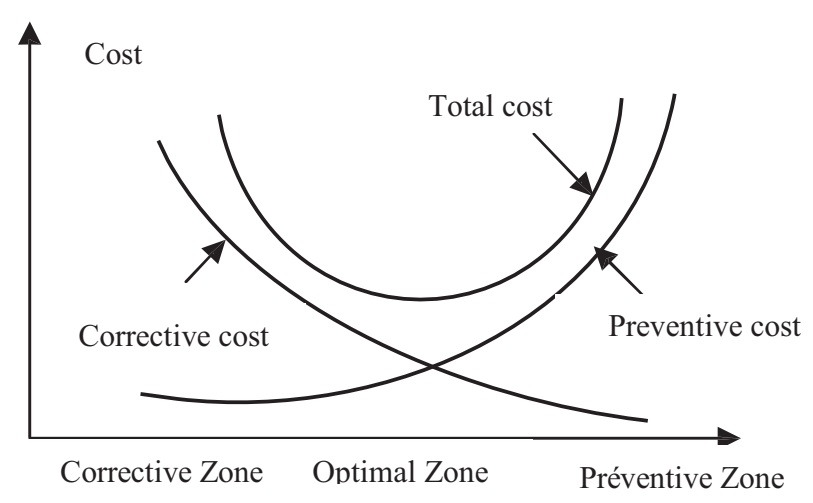

Fig. (1). Failures impact of equipment maintenance.

With the growing complexity of industrial equipments, optimal performance can only be guaranteed with an appropriated maintenance policy and a platform of maintenance has been developed. It is based on a reliability equipments analysis in order to model and simulate the dynamic behavior of these equipments. The results of the simulation allow the maintenance manager to choose the best policy to deploy with regard to availability and cost criterions

describing the process and methodology that have been used to set up the platform. We shall illustrate its use based on case studies. Then, we will conclude with the necessity of the integration of uncertainty that affects parameters of reliability laws when modeling failures, (Fig. 1).

\subsection{Establishment of the OMF Tool}

The maintenance optimization based on reliability can only be considered by the implementation of the developed tool "MBF" or "RCM" (Reliability Centered Maintenance) [3 - 6]. This implementation is done by a group project, in which different actors are involved (maintenance, production, operation, security, etc ...), which involves the following four steps:

- $\mathbf{1}^{\text {rs }}$ Step: Identification of all equipments that affect production (workshop) in their nomenclature. Then we made the selection of strategic equipment using the "ABC" method.

- $\mathbf{2}^{\text {nd }}$ step: Functional analysis of selected equipment. Analysis «AMDEC" (Analysis of Failure Mode Effect and their criticality), establishing sheets for each critical equipment and validation of leaves "AMDEC" by the project group.

- $\mathbf{3}^{\text {rd }}$ stage: Establishment of the maintenance plan and its validation by the project group.

- $4^{\text {th }}$ stage: Optimization of feedback, which is the most important phase of the implementation of the "MBF", introducing the indirect maintenance costs..

The objective of the "MBF" is the reduction of these costs incurred by downtime due to failures while controlling direct maintenance costs [3 - 6]. A maintenance policy is defined by a set of actions performed and ordered according to a certain strategy of future development. As a part of this research, we develop a reliability approach based on the analysis of the equipment maintenability to define correctly preventive maintenance actions and to undertaken best indice of quality. Such reliability analyses have been discussed in the scientific literature [5 - 8]. 


\section{APPLICATION}

In most cases, a manufacturing company with production process does not have the same stress reliability that other companies may have [6 - 9]. The security of our project is not taken in the first place, but a techno-economic optimum dependability of the production tool that is sought with maximum reliability. Dependability is the ability of an entity to satisfy one or more functions required under given conditions. It is generally characterized by parameters: ReliabilityAvailability-Maintainability and Safety (FMDS).

Faced with the real system, actors maintenance and reliability engineers must share their knowledge for equipment covered by the study. We must be able to determine the machines or parts of critical equipment, for which an improvement in the availability and a maintenance costs reduction have a significant effect on the company. This requires the establishment of needs a hierarchy, as well as functional analysis to highlight the most important gaps for equipments studied. The approach involved initially is decomposition into different sites (production workshops, and operating workshop) followed with an inventory of all equipments. The concept of human-machine cooperation is born after the advent of decision support tools as an assistant to a human decision maker and therefore the possibility shares tasks between them [6 - 8]. In these circumstances, the group uses MBF tool to get advice and a making decision. He leads the group in its approach to problem solving and bring it to discover the solution itself, therefore, it has the advantage of reducing costs maintenance. The AMDEC study is mainly used to optimize indirect costs Fig. (1). Indeed, is an intelligent diagnosis method to extent its predictions in a number of weaknesses, defects, abnormalities and failures at all the elements that contribute to making a product $(5 \mathrm{M})$. Influencing factors are internal or external, which have the effect of acting directly on the system reliability. This influence can be positive, causing reductions in the failures number, or contrary, have negative effects on reliability. The applied model is widely used and can combine a large amount of factors. To meet our need for modeling failure rate, we must take into account a limited number of factors, including the selection is made according to three criteria, (Fig. 2):

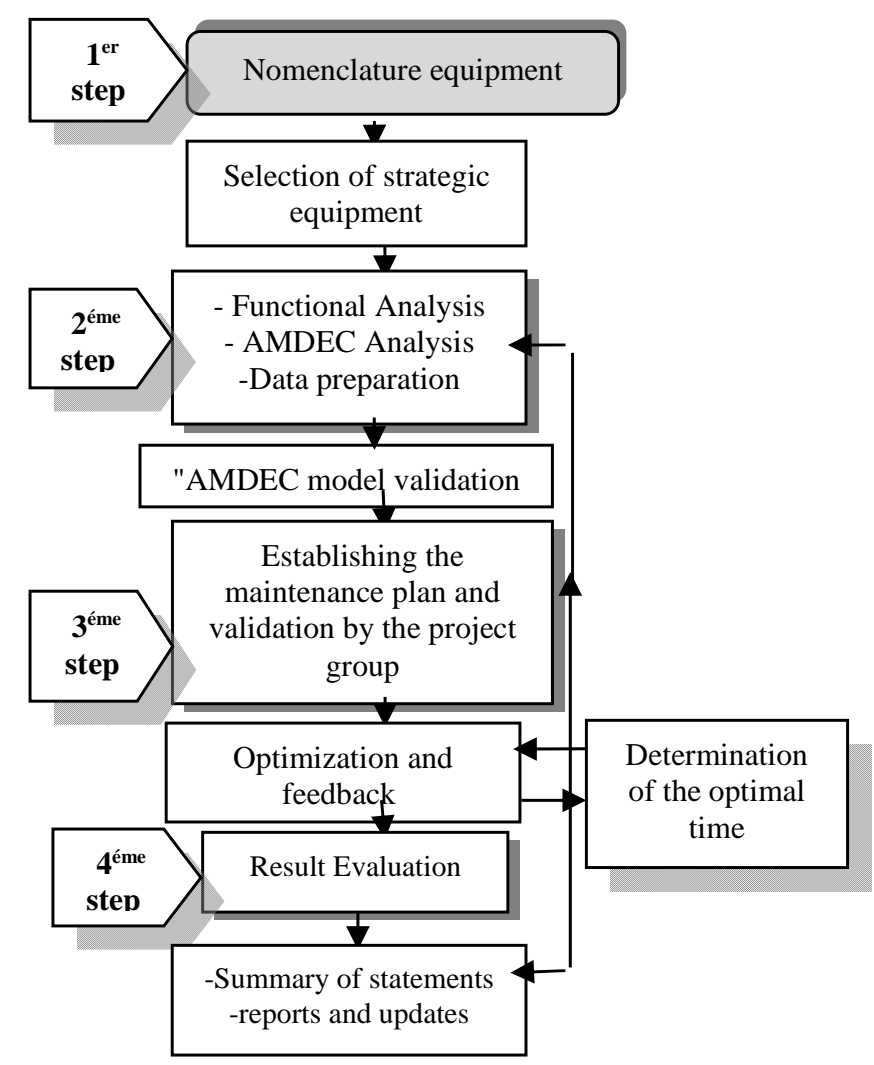

Fig. (2). Steps for setting up the "MBF" and transfering to "OMF".

$-1^{\text {st }}$ criteria: It is possible to measure or assess the state of the factors for each system.

$-2^{\text {nd }}$ criteria: Measurements and impact assessments should allow distinguishing between the different systems studied. 
$-3^{\text {rd }}$ criteria: Factors of influence are sufficiently chosen to justify the significant differences in reliability.

Note : Fig. (2) shows the overall schematics for any intervention by maintenance optimization, starting with the choice of strategic equipment ( $1^{\text {st }}$ step) to the critical element. The ( $3^{\text {rd }}$ step) is to choose the type of analysis, in our case it is the analysis of feedback, and the ( $4^{\text {th }}$ step) is the evaluation of the results found by reliability tools.

\subsection{The Principle of Manufacturing Division}

The recent problem that arises is how to divide all the equipment at more detailed levels to reach the one which we want to study, (Figs. 3, 4 and 5).

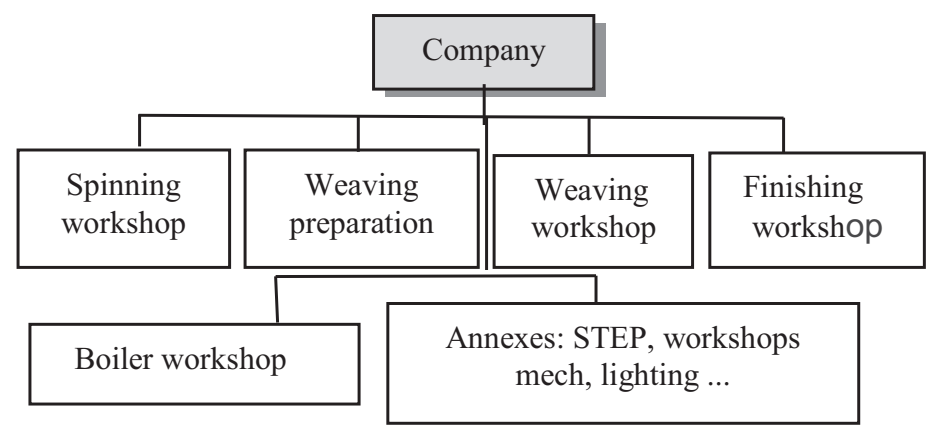

Fig. (3). Company zoning set.

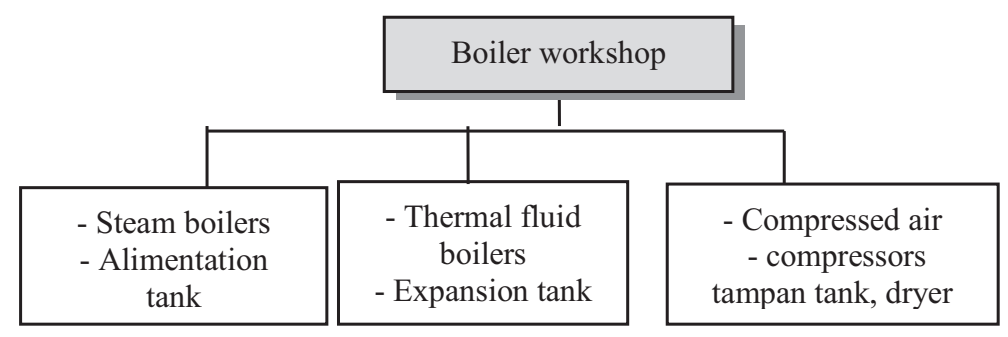

Fig. (4). Boiler workshop detail.

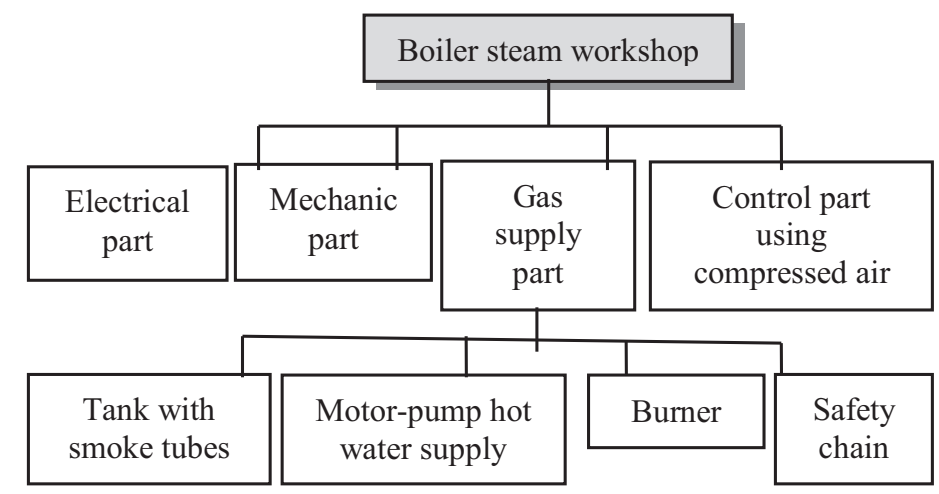

Fig. (5). Boiler workshop fonctionnal analysis.

The selection of critical equipment is achieved by using the method of "ABC" as a criterion in determining the number of failures in equipment. The "AMDEC" tool is used to finalize the determination of the critical elements.

The first division will be followed by a second leading down to the level of critical equipment to isolate him [7 - 11]. The Boiler workshop includes:

- Four boilers connected in parallel and fed to the steam system, each boiler is equipped with two multi-stage pumps connected in parallel.

- Three thermal fluid boilers equipped with three pumps of oil circulation. 
- Two vane compressors with two floors.

- A compressor vane one floor.

- A screw compressor.

These compressors are connected in parallel and supplying the compressed air system that operates the equipment production.

\subsection{System Analysis}

Initially we will decompose functionally a steam boiler.

\subsection{Decomposition of the Water Supply System Alimentation}

For this method "AMDEC" [10 - 12], a creative thinking is based on functional decomposition of the system into simple elements down to the level of the most basic components. AMDEC is a method that is essentially based on data functional treatment. Each subset has the functional relationships of its most basic organs, (Fig. 6).

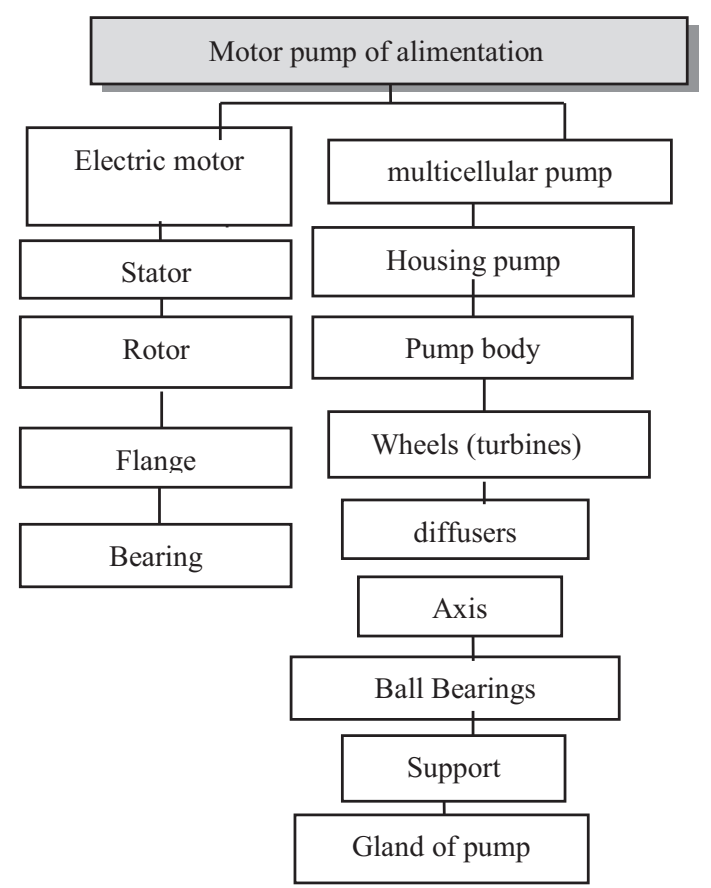

Fig. (6). Functional diagnozis of the feed pump.

\subsection{Material Classification}

The classification is mainly used as a basis for establishing a preventive maintenance program and to measure the effects of this maintenance.

\subsection{Classification Criteria}

There are two possible criteria for classification consisting of practice which does not treat the material on a level playing field, but according to specific criteria [7 - 11].

a- Working conditions.

The material can be classified into two categories:

- Material in high demand, it is the case of equipment operating in continuous mode $(3 \times 8)$.

- Material moderately requested is for operate intermittently case. 


\section{b- Equipment status.}

The criterion of this classification is to compare the condition of equipment with operational needs: It means that equipment can be used to perform certain operations although his general condition is degraded compared to new equipment.

\subsection{Collection Data}

To establish good reliability study, it is advantageous to raise the number of failures of each organ from the historical record of each equipment (2009-2010).

\section{DATA ANALYSIS}

For equipment consisting of a large number of bodies, the "MTBF" equipment has a meaning at the availability of equipment $[12,13,15]$.. The "MTBF" equipment depends on the knowledge of the reliability of its components, which allows engineer to define a maintenance policy. Reliability should be determined for each component constituting the entire equipment. The exploitation of historical data should consider the following criteria:

- The number of facilities studied their working conditions and the respective time use.

- The number of installed equipment components.

- The time of operation of each component relative to the running time of the equipment.

- The maintenance policy applied to these facilities (Corrective Maintenance, Maintenance Condition, Monitoring Systematic).

In the case of multiple devices installed, it would logically verify that the conditions of use and time of solicitation are identical. It is essential to analyze the causes of failures occurring for each member and ensure that the study population is homogeneous. We must look if it is a fortuitous failure (i.e. life), a failure due to aging, deterioration due to moisture of equipment, improper repair or incorrect installation.

The data are collected from historical records of workshop boiler which is the production goal and therefore there is the main product goal . the historical is classified according to the following pattern: Historical of the failures for boiler workshop during the period (2009-2010) are given below.

- Steam boilers have developed (84) failures

- The thermal fluid boilers have developed (32) failures

- The vane compressors with two floors have developed (17) failures

- The vane compressor with one floor has developed (09) failures

- The screw air compressor compressed has developed (14) failures

\subsection{Equipment Classification}

Using the model "or Pareto ABC" we can determine the key parameters involved in evaluating the degradation of sensitive equipment and requiring optimization of the production line or exploitation, (Tables $\mathbf{1}$ and 2). This analysis method of critical equipment is used to select the type of maintenance required. This selection of maintenance is a major advantage for optimizing the use and operation of equipment, and shall be applied to manufacturing company, in particular, to improve the costs of maintenance and operation.

Table 1. Equipment clasification.

\begin{tabular}{|c|c|c|c|c|}
\hline Designation & \% Classification & Freq. & Cumul. & \% of Cumul. \\
\hline Boiler steam & 20 & 84 & 84 & 54 \\
\hline Thermal fluid boiler & 40 & 32 & 116 & 74 \\
\hline Two-stage compressor & 60 & 17 & 133 & 85 \\
\hline Screw compressor & 80 & 14 & 147 & 94 \\
\hline A single stage compressor & 100 & 09 & 156 & 100 \\
\hline
\end{tabular}


Table 2. Summary of failures (a: number of failure).

\begin{tabular}{|c|c|c|c|c|c|}
\hline $\mathbf{N}^{\circ}$ & Organ Designation & $\mathbf{a}$ & $\mathbf{N}^{\circ}$ & Organ Designation & $\mathbf{a}$ \\
\hline 1 & Ball bearings of the pumpe & 29 & 11 & Electric pump motor & 05 \\
\hline 2 & Roller bearing of the pump & 09 & 12 & The pump and motor couple & 04 \\
\hline 3 & purge valve hot water & 03 & 13 & Safety valve spring & 01 \\
\hline 4 & Aeration valve & 04 & 14 & Air pressure & 01 \\
\hline 5 & Water level indicator & 04 & 15 & electromagnetic valve & 01 \\
\hline 6 & Gland of the pump & 05 & 16 & Splitter water level & 01 \\
\hline 7 & Supply line hot water & 03 & 17 & Manhole maintenance & 02 \\
\hline 8 & Body of the feed pump & 03 & 18 & main fan & 01 \\
\hline 9 & Check valve of the pump & 02 & 19 & Internal float water level & 02 \\
\hline 10 & Ring in pump seal & 04 & & & $\mathbf{8 4}$ \\
\hline
\end{tabular}

Result: The organ with the highest criticality frequency is the ball bearing.

\subsection{ABC Method}

The ABC method classifies degradation priority of the equipment, Fig. (7) [10 - 12].

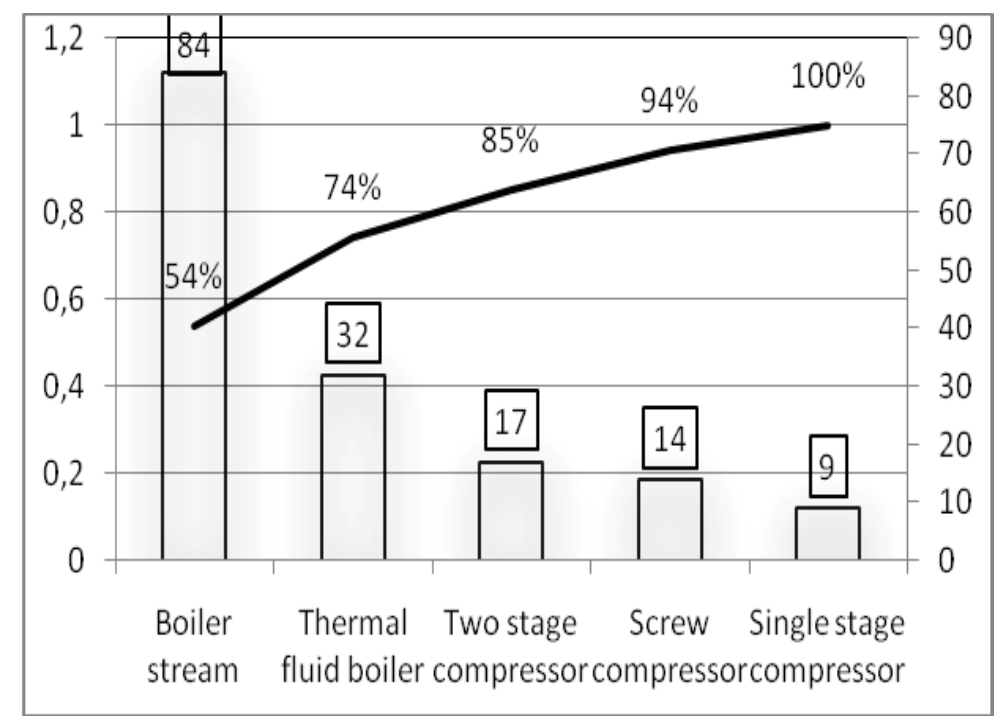

Fig. (7). ABC model of equipment damaged.

The "ABC" model allowed us to classify boiler equipment into three categories (A, B and C). Class "A" represents a subset of special monitoring and class " $\mathrm{B}$ " and " $\mathrm{C}$ " represent subsets of specific monitoring. The reliability analysis of this equipment will allow us to secure the type of maintenance

\section{ANALYSIS OF ALIMENTATION PUMP}

The "AMDEC" pump analysis is used to determine the critical organ of equipment, Table $\mathbf{3}$. This table shows the well criticality index of body pump, which allows the maintenance department to determine priorities action to reduce the number of failures and increase the time of the equipment operation.

Table 3. AMDEC analysis of the supply pump organ.

\begin{tabular}{|c|c|c|c|c|c|c|c|c|c|}
\hline \multicolumn{10}{|c|}{ System: Boiler Steam Subsystem: Supply Pump } \\
\hline \multirow[t]{2}{*}{ Organ } & \multirow[t]{2}{*}{ Organ Function } & \multirow[t]{2}{*}{ Failure Mode } & \multirow[t]{2}{*}{\begin{tabular}{l|} 
Cause \\
\end{tabular}} & \multirow{2}{*}{$\begin{array}{c}\text { Effect on } \\
\text { System }\end{array}$} & \multicolumn{4}{|c|}{ Criticality } & \multirow{2}{*}{ Remedying } \\
\hline & & & & & & $\mathbf{G}$ & $\mathbf{D}$ & IPR & \\
\hline Body & Pump support & Deformation & vibration & Failure of bore & 1 & 2 & 2 & 4 & To repair \\
\hline Pump body & Contains wheels & Bore ovality & wear, corrosion & $\begin{array}{c}\text { Operational } \\
\text { Failure }\end{array}$ & 1 & 4 & 1 & 4 & To repair \\
\hline wheels & Fluid velocity increases & Not normal noise & wear, corrosion & Increases of fluid level & 1 & 3 & 3 & 9 & To change \\
\hline
\end{tabular}


(Table $\square$ ) contd.....

\begin{tabular}{|c|c|c|c|c|c|c|c|c|c|}
\hline \multicolumn{10}{|c|}{ System: Boiler Steam Subsystem: Supply Pump } \\
\hline \multirow[t]{2}{*}{ Organ } & \multirow[t]{2}{*}{ Organ Function } & \multirow[t]{2}{*}{ Failure Mode } & \multirow[t]{2}{*}{ Cause } & \multirow{2}{*}{$\begin{array}{c}\text { Effect on } \\
\text { System }\end{array}$} & \multicolumn{4}{|c|}{ Criticality } & \multirow{2}{*}{ Remedying } \\
\hline & & & & & $\mathbf{F}$ & $\mathbf{G}$ & D & IPR & \\
\hline Diffusers & Water channels in the wheels & Deformation & wear, corrosion & $\begin{array}{c}\text { Operational } \\
\text { Failure } \mathrm{t}\end{array}$ & 1 & 1 & 3 & 3 & To change \\
\hline Axis & Transmits rotational movement & Failure, deformation & wear, corrosion & Failure of pump & 1 & 4 & 1 & 4 & To change \\
\hline Bearings & Supporting axis & Wear, rupture & Vibration, wear & Hot and blocking & 1 & 4 & 1 & 4 & To change \\
\hline Ball bearing & Guiding axis & Rupture, blocking & Vibration, wear & Failure of pump & 3 & 4 & 1 & 12 & To change \\
\hline Gland of pump & Ensure that the seals & Leaking pipes pump & wear, corrosion & Increases of fluid level & 3 & 3 & 1 & 9 & To replace \\
\hline
\end{tabular}

The same method is used to analyze the compressor, (Table 4).

Table 4. AMDEC analysis of two-stage compressor.

\begin{tabular}{|c|c|c|c|c|c|c|c|c|}
\hline \multicolumn{9}{|c|}{ System pallets compressor / subsystem: mechanical part } \\
\hline \multirow[t]{2}{*}{ Organ } & \multirow[t]{2}{*}{ State Function } & \multirow[t]{2}{*}{ Failure Mode } & \multirow[t]{2}{*}{ Cause } & \multirow{2}{*}{ Effect On The System } & \multicolumn{3}{|c|}{ Criticité } & \multirow{2}{*}{ Action à Engager } \\
\hline & & & & & $\mathbf{F}$ & $\mathbf{G}$ & \begin{tabular}{|l|l|} 
D & IPR \\
\end{tabular} & \\
\hline Body & contains the rotors and pallets & Wear bore ovality & Failure & Pressure drop & 1 & 2 & \begin{tabular}{|l|l|}
2 & 4 \\
\end{tabular} & To repair \\
\hline Oil pump & Rotors lubrificating & abnormal noise & Gear failure & Warm & 1 & 3 & 3 & To repair \\
\hline oil separator & separating the oil from the air & presence in the oil air & Aging & Oil consumption & 1 & 3 & 3 & To change \\
\hline Coupling element & $\begin{array}{c}\text { Compressor and engine } \\
\text { connecting }\end{array}$ & Failure & Desalignemnt & Compressor shutdown & 2 & 3 & 6 & To change \\
\hline oil hose & carrying oil to the radiator & leaking oil & Aging & Compressor shutdown & 1 & 3 & 3 & To change \\
\hline rotary joint & seals leak & Leak side engine & Wear & Compressor shutdown & 3 & 3 & 9 & To change \\
\hline Toric ring & $\begin{array}{l}\text { seals between the compressor } \\
\text { stages }\end{array}$ & body leaking & Aging & Oil consumption & 3 & 3 & 9 & To change \\
\hline
\end{tabular}

Result: IPR: Priority on Risk Index" is the ball bearing.

F: frequency degree; G: Gravity degree; D: Detectability degree

\subsection{Determination of the Reliability Parameters of the Selected Body}

\section{Case of the Alimentation Pump Bearing}

The calculation of the reliability parameters depends primarily on the estimated distribution function which is defined by the equation (1).

$$
F_{\text {est }}=\frac{i-0.3}{N+0.4}
$$

\section{Preparation of Historical Data}

Plotting points (ti, fi) is clear on the role of "Weibull" or "Alain plait". From the data we obtained two lines "D1" and "D2" that represent two different sample sizes. As the time difference between life sufficiently large ranges seven " $\mathrm{t} 7$ " and eight " $\mathrm{t} 8$ ", so we see a change in the law of life " $\mathrm{t}$ " (from $\beta 1=1.2 ; \eta 1=580$ heures to $\beta 2=1.5$, $\eta 2=$ 2500heures).

This study gives two different straight lines with different distributions of functions, see equation (1) and (Table 5).

Table 5. Bearing reliability result.

\begin{tabular}{|c|c|c|c|c|c|c|}
\hline $\mathbf{t i}$ & Rank brut & $\begin{array}{c}\text { Rank } \\
\text { Corrected }\end{array}$ & F Theo. & R Theo. & Taux $\boldsymbol{\lambda}(\mathbf{t})$ & $\mathbf{D}_{\mathbf{N}, \boldsymbol{q}_{\mathbf{a}}}$ \\
\hline 64 & 1 & 1 & 0.07 & 0.93 & 1.33 & 0.01 \\
\hline 144 & 2 & 2 & 0.17 & 0.83 & 1.57 & 0.02 \\
\hline 160 & 3 & 3 & 0.19 & 0.81 & 1.6 & 0.05 \\
\hline 224 & 4 & 4 & 0.27 & 0.73 & 1.71 & 0.05 \\
\hline 352 & 5 & 5 & 0.42 & 0.58 & 1.87 & 0.01 \\
\hline 496 & 6 & 6 & 0.56 & 0.44 & 2.01 & 0.06 \\
\hline 608 & 7 & 7 & 0.65 & 0.35 & 2.09 & 0.06 \\
\hline 2544 & 8 & 8 & 0.64 & 0.36 & 0.605 & 0.04 \\
\hline 3520 & 9 & 9 & 0.81 & 0.19 & 0.712 & 0.05 \\
\hline
\end{tabular}


(Table $\square$ ) contd.....

\begin{tabular}{|c|c|c|c|c|c|c|}
\hline (Table $\square$ contd..... & Rank brut & $\begin{array}{c}\text { Rank } \\
\text { Corrected }\end{array}$ & F Theo. & R Theo. & Taux $\lambda(\mathbf{t})$ \\
\hline 3872 & 10 & 10 & 0.85 & 0.15 & 0.747 \\
\hline 5280 & 11 & 11 & 0.95 & 0.05 & 0.00 \\
\hline
\end{tabular}

Table 5 allows determining the cumulative function and the reliability of the Weibull model is considered an adaptive model for variable damage over time. Tables $(\mathbf{5}$ and $\mathbf{6})$ show the estimated functions and theoretical cumulative function and reliability function are determined by the Weibull function in these two parameters. This analysis shows the adaptation of the Weibull law, see Fig. (8). As depicted in the graph of "Weibull", several segments with different values of " $\beta$ " must lead a choice on the quality of organs and their diagnosis [12, 14 - 16]. Indeed, this hypothesis is true in our case, in practice it was found that the phenomenon is due to the change of bearings, as using two different brands. The problem added the deformation of the structure, which leads to a problem of bearings quality, so there is a mixture of laws "Weibull" $[12,13]$. The model takes into account overall proportions of each part, see the equations (2), (3), (4), (5), (6) and (7). The determination of the reliability of the population is given by the final equation (7) and treated part of equations (2), (3), (4), (5) and (6).

Table 6. Traitement of bearing data historic.

\begin{tabular}{|c|c|c|c|c|}
\hline ti & Rank brut & $\begin{array}{c}\text { Rank } \\
\text { Corrected }\end{array}$ & $\begin{array}{c}\mathbf{F} \\
\text { estimated }\end{array}$ & $\begin{array}{c}R \\
\text { estimated }\end{array}$ \\
\hline 64 & 1 & 1 & 0.006 & 0.94 \\
\hline 144 & 2 & 2 & 0.15 & 0.85 \\
\hline 160 & 3 & 3 & 0.24 & 0.76 \\
\hline 224 & 4 & 4 & 0.32 & 0.68 \\
\hline 352 & 5 & 5 & 0.41 & 0.59 \\
\hline 496 & 6 & 6 & 0.50 & 0.50 \\
\hline 608 & 7 & 7 & 0.59 & 0.41 \\
\hline 2544 & 8 & 8 & 0.68 & 0.32 \\
\hline 3520 & 9 & 9 & 0.76 & 0.24 \\
\hline 3872 & 10 & 10 & 0.85 & 0.15 \\
\hline 5280 & 11 & 11 & 0.94 & 0.06 \\
\hline
\end{tabular}

Reliability is managed by the following specific equations

$$
\begin{gathered}
e^{-\left(\frac{t}{\eta 1}\right)(\beta 1)}=R 1 \quad ; \mathrm{t} \leq \mathrm{t} 7 \\
e^{-\left(\frac{t}{\eta 2}\right)(\beta 2)}=R 2 \quad ; \mathrm{t}>\mathrm{t} 7 \\
\frac{\beta 1}{\eta 1}\left(\frac{t}{\eta 1}\right)^{(\beta 1-1)}=\lambda 1 \\
\frac{\beta 2}{\eta 2}\left(\frac{t}{\eta 2}\right)^{(\beta 2-1)}=\lambda 2 \\
P 1=\frac{n 1}{n 1+1}=\frac{7}{11}=0.64 ; P 2=0.36
\end{gathered}
$$




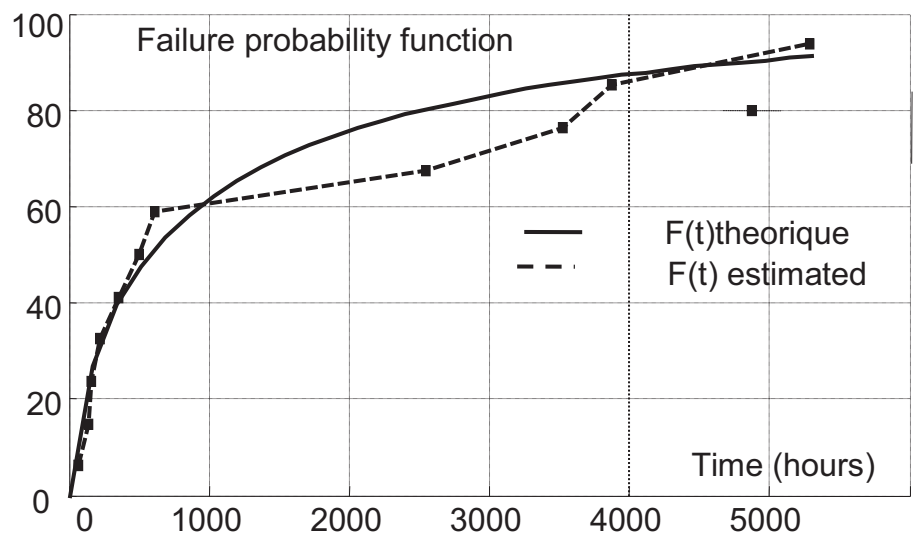

Fig. (8). Theoretical and estimated reliability distribution.

In conclusion, the study of the ball bearing from the boiler feed pump confirms the establishment of positive reliability from (REX). This reliability is of great importance for optimizing boiler operation and, is the driving force for the factory, floor spinning and weaving at the complex.

\subsection{Historical Resultat Analysis}

Here attached is the summary table and comparison of results determined by calculation using the reliability law.

\subsection{Application of Correlation Tests}

The test of "Kolmogorov Smirnov" is checked at any point, we can conclude that the theoretical law coincides with that drawn from the sample. A risk $(5 \%)$ between the two laws is shown as shown in Table 5. The $\mathrm{D}_{11}$ value $(0.05)=$ 0.391 is taken from the digital table "Kolmogorov Smirnov" [1, 2, 5]

The calculation of the MTBF is as follows:

$$
M T B F_{\text {global }}=\mathrm{p} 1 \cdot M T B F_{1}+\mathrm{p} 2 \cdot M T B F_{2}
$$

"x1" and "x2" are identified in numerical "Alain plait" table.

$$
\begin{gathered}
M T B F_{1}=\mathrm{x}_{1 .} \eta_{1}=0.9407 .580=545.60 \text { heures } \\
M T B F_{2}=\mathrm{x} 2 . \eta 2=0.9027 .2500=2256.75 \text { heures }
\end{gathered}
$$

$$
M T B F_{\text {global }}=0.64 * 545.6+0.36 * 02256.75=1161.61 \text { heures }
$$

The life value is (72.6) days or ( 3 months and a half) for a regime of 16heures operation per day and twenty two working days per month.

$$
\begin{gathered}
R 1_{(\mathrm{MTBF})}=0.64 \\
R 2_{(\mathrm{MTBF})}=0.36 \\
R_{\text {(global) }}=0.64 * 0.39+0.36 * 0.42=0.40
\end{gathered}
$$

In Fig. (8) we notice that the test for "Kolmogorov Smirnov" is checked, and the figures (Fth and Fest) are much closed and are in accordance with each other. 


\section{CONCLUSION}

This work has shown the feasibility and possibility of building a maintenance optimization method in enterprises. The implementation of AMDEC approach shows its contribution in reducing maintenance costs and achieves the following step:

-Identify critical functions for the system, -Define the maintenance policy for the system and its components.

We deduce from this research an optimized maintenance time by equipment reliability of boiler workshop at "Denitex-Sebdou" level. The tools are based on models of "Weibull" and the AMDEC method, which give good results analysis on equipment fault analysis. With reliability estimator including degradation index $(\beta)$ we can determine the good diagnosis of the system, its value is between 0.5 and 3.5 .

This parameter is of great importance for estimating the reliability and type of maintenance required to manage the system in operation and in order to avoid sudden failures and catalectic degradation, which are very expensive for the company "Denitex Sebdou". Following this study, the maintenance department has a good production during the following year an agreement of the production facilities and exploitation. This production and operation help in optimizing the exploitation equipment and using tools. During the $1^{\text {st }}$ half year time of this study, no default was recorded at the tested equipment because of proper monitoring of critical equipment and analysis of the failing organ. This work established shows the positive impact on the reliability tool of equipment maintenance, in particularly, the method of Pareto, and it can directly affect the cost of maintenance and thus the overall cost of production

\section{CONSENT FOR PUBLICATION}

Not applicable.

\section{CONFLICT OF INTEREST}

The authors declare no conflict of interest, financial or otherwise.

\section{ACKNOWLEDGEMENTS}

Declared none.

\section{REFERENCES}

[1] M. Rausand, and K. Oien, "The basic concepts of failure analysis", Reliab. Eng. Syst. Saf., vol. 53, pp. 73-83, 1996. [http://dx.doi.org/10.1016/0951-8320(96)00010-5]

[2] R. Dekker, "Applications of maintenance optimization models: a review and analysis", Reliab. Eng. Syst. Saf., vol. 51, no. 3, pp. 229-240, 1996. [http://dx.doi.org/10.1016/0951-8320(95)00076-3]

[3] C. Hua, and T. Nakagawa, "Optimal preventive maintenance policies for a shock model with given damage level", J. Qual. Mainten. Eng., vol. 11 , no. 3, pp. 216-227, 2005.

[http://dx.doi.org/10.1108/13552510510616432]

[4] D.M. Richet, and D. Gabriel, Maintenance basée sur la fiabilité, édition., Masson: Paris, 1996.

[5] Z.W. Gilles, Optimisation de la maintenance par la fiabilité, Maintenance et Entreprise: №454, Paris, 1992.

[6] D. Gabriel, D.M. Richet, D.C. Noberto, Eds., Mise en xuvre d'un bechmarking sectoriel pour améliorer l'organisation de la maintenance des PMEdes PME, 1995.

[7] AFNOR, Recueil des normes françaises XOAFNOR, 1998.

[8] D. M., Eds, Maintenance basée sur la Fiabilité, édition, Masson: Paris, 1996.

[9] J. Foucher, Pratique de l'AMDEC, Edition., Dunod: Paris, 2004.

[10] J.C. Ligeron, and P. Lyonnet, "La fiabilité en exploitation; organisation et traitement des données", vol. 2. Edition Lavoisier: Paris, 1993.

[11] F. Monchy, Maintenance, Méthode et Organisation, édition., Usine Nouvelle: Paris, 2004.

[12] V. Pareto, “Cours d'économie politique”, University of Lausanne., vol. 1. Switerzland, 1896.

[13] J. Bufferne, Fiabiliser les équipements industriels édition Eyrolles, 2008.

[14] J. Ligeron, A. Delage, and M. Neff, Fiabilité en exploitation, édition Lavoisier, .

[15] Y. Martin, and N. Guirago, J. Faucher. and P. Lyonnet, Détermination par simulation d'une politique de maintenance., Paris ISDF, 1994. 
[16] J. Bufferne, Total productive maintenance, Paris: édition Eyrolles, 2007.

\section{(C) 2017 Bachir et al.}

This is an open access article distributed under the terms of the Creative Commons Attribution 4.0 International Public License (CC-BY 4.0), a copy of which is available at: https://creativecommons.org/licenses/by/4.0/legalcode. This license permits unrestricted use, distribution, and reproduction in any medium, provided the original author and source are credited. 